\title{
Decreased TCA cycle rate in the rat brain after acute 3-NP treatment measured by in vivo ${ }^{1} \mathrm{H}-\left\{{ }^{13} \mathrm{C}\right\}$ NMR spectroscopy
}

\author{
Pierre-Gilles Henry, ${ }^{*}$ Vincent Lebon, ${ }^{*}$ Françoise Vaufrey, ${ }^{*}$ Emmanuel Brouillet, $\dagger$ \\ Philippe Hantraye $\dagger$ and Gilles Bloch* \\ ${ }^{*}$ CEA and $\dagger U M R$ CEA-CNRS 2210, Service Hospitalier Frédéric Joliot, Orsay, France
}

\begin{abstract}
Inhibition of succinate dehydrogenase (SDH) by the mitochondrial toxin 3-nitropropionic acid (3-NP) has gained acceptance as an animal model of Huntington's disease. In this study ${ }^{13} \mathrm{C}$ NMR spectroscopy was used to measure the tricarboxylic acid (TCA) cycle rate in the rat brain after 3-NP treatment. The time course of both glutamate $\mathrm{C} 4$ and $\mathrm{C} 3{ }^{13} \mathrm{C}$ labelling was monitored in vivo during an infusion of $\left[1-{ }^{13} \mathrm{C}\right]$ glucose. Data were fitted by a mathematical model to yield the TCA cycle rate $\left(V_{\mathrm{tca}}\right)$ and the exchange rate between $\alpha$-ketoglutarate and glutamate $\left(V_{x}\right)$. 3-NP treatment induced a $18 \%$ decrease in $V_{\text {tca }}$ from $0.71 \pm 0.02 \mu \mathrm{mol} / \mathrm{g} / \mathrm{min}$ in the control group to
\end{abstract}

$0.58 \pm 0.02 \mu \mathrm{mol} / \mathrm{g} / \mathrm{min}$ in the $3-\mathrm{NP}$ group $(p<0.001) . V_{x}$ increased from $0.88 \pm 0.08 \mu \mathrm{mol} / \mathrm{g} / \mathrm{min}$ in the control group to $1.33 \pm 0.24 \mu \mathrm{mol} / \mathrm{g} / \mathrm{min}$ in the $3-\mathrm{NP}$ group $(p<0.07)$. Fitting the $\mathrm{C} 4$ glutamate time course alone under the assumption that $V_{\mathrm{x}}$ is much higher than $V_{\text {tca }}$ yielded $V_{\text {tca }}=0.43 \mu \mathrm{mol} / \mathrm{g} / \mathrm{min}$ in both groups. These results suggest that both $V_{\text {tca }}$ and $V_{\mathrm{x}}$ are altered during 3-NP treatment, and that both glutamate $\mathrm{C} 4$ and $\mathrm{C} 3$ labelling time courses are necessary to obtain a reliable measurement of $V_{\text {tca }}$.

Keywords: brain, ${ }^{13} \mathrm{C}$ NMR spectroscopy, glutamate, 3-nitropropionic acid, rat, TCA cycle.

J. Neurochem. (2002) 82, 857-866.
Huntington's disease (HD) is a hereditary neurodegenerative disorder characterized by abnormal movements and cognitive deficits. These symptoms are associated with a progressive degeneration of GABAergic neurones in the striatum (Harper 1991). Although the mechanism leading to neurodegeneration is unknown, there is growing evidence that it could result from a partial energy impairment and subsequent indirect excitotoxic neuronal damage (Brouillet et al. 1999; Beal 2000). Consistent with this hypothesis, chronic treatment with the mitochondrial toxin 3-nitropropionate (3-NP), an irreversible inhibitor of succinate dehydrogenase (SDH), produces symptoms and lesions in animals very similar to those observed in HD (Brouillet et al. 1999). Several studies have used ${ }^{1} \mathrm{H}$ NMR spectroscopy to assess changes in metabolite concentrations after 3-NP treatment in vivo (Beal et al. 1993; Jenkins et al. 1996; Dautry et al. 1999; Lee et al. 2000) and ex vivo (Tsai et al. 1997; Dautry et al. 2000). In one study, the effect of 3-NP treatment was investigated in mice using ${ }^{13} \mathrm{C}$ NMR spectroscopy ex vivo after infusion of $\left[1-{ }^{13} \mathrm{C}\right]$ glucose and $\left[2-{ }^{13} \mathrm{C}\right]$ acetate (Hassel and Sonnewald 1995). However, none to our knowledge has tried to directly measure oxidative metabolism impairment in vivo using a functional approach.
${ }^{13} \mathrm{C}$ NMR is a unique tool for investigating metabolic fluxes in biological systems. Dynamic ${ }^{13} \mathrm{C}$ NMR spectroscopy has been used to measure the TCA cycle rate in the brain under various physiological conditions in rats and humans during an infusion of ${ }^{13} \mathrm{C}$-labelled glucose (Mason et al. 1992, 1995, 1999; Hyder et al. 1996, 1997, 1999; Sibson et al. 1998; Shen et al. 1999; Blüml et al. 2001; Chen et al. 2001; Gruetter et al. 2001). TCA cycle intermediates cannot be detected by NMR in vivo due to their low concentration. Therefore NMR measurements of the TCA cycle rate rely on the detection of ${ }^{13} \mathrm{C}$ incorporation into the large pool of glutamate, which is in exchange with $\alpha$-ketoglutarate. Using a mathematical analysis (Chance $e t$ al.

Received October 17, 2001; revised manuscript received May 5, 2002; accepted May 5, 2002.

Address correspondence and reprint requests to Gilles Bloch, Service Hospitalier Frédéric Joliot, 4 place du général Leclerc, 91401 Orsay cedex, France. E-mail: gilles.bloch@cea.fr

Abbreviations used: FE, fractional enrichment; HD, Huntington's disease; 3-NP, 3-nitropropionic acid; ppm, parts per million; POCE, proton-observed carbon-edited; SDH, succinate dehydrogenase; TCA, tricarboxylic acid; $V_{\text {tca }}$, rate of tricarboxylic acid cycle; $V_{\mathrm{x}}$, exchange rate between $\alpha$-ketoglutarate and glutamate. 
1983), the TCA cycle rate $\left(V_{\text {tca }}\right)$ and the exchange rate between $\alpha$-ketoglutarate and glutamate $\left(V_{\mathrm{x}}\right)$ can be calculated from glutamate ${ }^{13} \mathrm{C}$-labelling time courses. Our purpose was to demonstrate that this methodological approach can be applied to measure the impairment of brain oxidative metabolism induced by 3 -NP treatment.

During an infusion of $\left[1-{ }^{13} \mathrm{C}\right]$ glucose, glutamate $\mathrm{C} 4$ becomes labelled in the first turn of the TCA cycle, whereas C3 is labelled in the second turn. In many studies, due to the lower signal-to-noise ratio and spectral resolution of in vivo NMR spectra, only glutamate C4 labelling time course was recorded (Hyder et al. 1996, 1997, 1999; Sibson et al. 1998; Mason et al. 1999; Shen et al. 1999; Chen et al. 2001). In this case, $V_{\mathrm{x}}$ could not be determined and was generally assumed to be high compared with $V_{\text {tca }}$. However, this assumption may not be valid in pathological conditions. Recently, a new method was presented to measure both glutamate $\mathrm{C} 4$ and $\mathrm{C} 3$ labelling time courses even though both signals strongly overlap (Henry et al. 2000). This method was used here in order to avoid any assumption on $V_{\mathrm{x}}$.

In this context, the objectives of the present work were: (i) to measure quantitatively the alteration of oxidative metabolism after 3-NP treatment in the rat brain and (ii) to evaluate whether the measurement of glutamate C3 labelling, in addition to $\mathrm{C} 4$ labelling, significantly improves the accuracy on the $V_{\text {tca }}$ measurement.

\section{Materials and methods}

\section{Animal preparation and glucose infusion}

All experimental procedures were performed in strict accordance with the recommendations of the European Community (86/609/ EEC) and the French National Committee (87/848) for care and use of laboratory animals. Two groups of Sprague-Dawley rats were studied: one control group (weight $324 \pm 21 \mathrm{~g}, n=5$ ) and one 3 -NP group (weight $303 \pm 56 \mathrm{~g}, n=5$ ). 3-NP was dissolved in saline and the $\mathrm{pH}$ of the solution was adjusted to 7.4 using $5 \mathrm{M}$ sodium hydroxide. Animals in the 3 -NP group were given a single intraperitoneal dose of $3-\mathrm{NP}(25 \mathrm{mg} / \mathrm{kg}) 24 \mathrm{~h}$ before the NMR measurement. This dose has been shown to induce partial SDH inhibition for more than $24 \mathrm{~h}$ (Brouillet et al. 1998). All animals were fasted overnight to reduce basal glycaemia. On the day of the experiment, animals were tracheotomized and ventilated with a $70 \% / 30 \% \mathrm{~N}_{2} \mathrm{O} / \mathrm{O}_{2}$ mixture and 3\% isoflurane. The left femoral artery and vein were cannulated for blood sampling and glucose infusion, respectively. Animals were positioned prone in a dedicated frame and their head secured by a bite-bar and ear rods. The scalp was removed to minimize contamination of spectra by lipid signal. The ${ }^{1} \mathrm{H}$ and ${ }^{13} \mathrm{C}$ surface probes were positioned above the head and centered $2 \mathrm{~mm}$ posterior to bregma. After surgery, isoflurane was discontinued and replaced by $\alpha$-chloralose (initial dose $80 \mathrm{mg} / \mathrm{kg}$ i.p. then $20 \mathrm{mg} / \mathrm{kg}$ i.p. every $40 \mathrm{~min}$ ). Body temperature was monitored using a rectal probe and maintained to $37.5^{\circ} \mathrm{C}$ using warm water circulation. Ventilation was monitored using a blood gas analyser (ABL5, Radiometer, Copenhagen, The Netherlands). No difference in physiological parameters was observed between the control and the 3-NP group. (control group: $\mathrm{pH}=7.34 \pm 0.04$, $\mathrm{pCO}_{2}=40 \pm 5, \quad n=5 ; \quad 3-\mathrm{NP}$ group: $\mathrm{pH}=7.33 \pm 0.05$, $\mathrm{pCO}_{2}=41 \pm 6, n=5$ ). $\mathrm{pO}_{2}$ was maintained above $100 \mathrm{mmHg}$ in all animals. Plasma glucose concentration was measured using the glucose oxidase method (Beckman Coulter, Fullerton, CA, USA).

After adjustment of spectroscopic parameters, a bolus of $99 \%$ enriched $\left[1-{ }^{13} \mathrm{C}\right]$ glucose $(20 \% \mathrm{wt} / \mathrm{vol})$ was infused through the left femoral vein at an exponentially decaying rate over $5 \mathrm{~min}$. Then $66 \%$-enriched $\left[1-{ }^{13} \mathrm{C}\right]$ glucose was infused at a constant rate until the end of the experiment. The infusion protocol was optimized to achieve a stable hyperglycaemic plateau over $120 \mathrm{~min}$ and a stable isotopic enrichment of plasma glucose.

Due to the catheter length required to work on a whole-body magnet, it was not possible to collect blood samples during glucose infusion in the in vivo NMR experiments. Therefore, the time course of plasma glucose fractional enrichment (FE) was measured on the bench under identical anaesthesia and infusion conditions over $80 \mathrm{~min}$. In this bench study, the plasma glucose concentration was raised from $7.8 \pm 1.7 \mathrm{mM}(t=0)$ to $25 \pm 2.2 \mathrm{mM}(t=2.5 \mathrm{~min})$ in the control group $(n=5)$ and from $7.8 \pm 0.6 \mathrm{~mm}(t=0)$ to $28.9 \pm 1.7 \mathrm{~mm}(t=2.5 \mathrm{~min})$ in the $3-\mathrm{NP}$ group $(n=5)$. The glucose concentrations at the end of the time course were $23.3 \pm 9.4 \mathrm{~mm}$ in the control group and $21.6 \pm 5.6 \mathrm{~mm}$ in the 3 -NP group. Plasma glucose FE at $t=10 \mathrm{~min}$ was $63 \pm 6 \%$ in the control group and $65 \pm 4 \%$ in the 3-NP group. Plasma glucose $\mathrm{FE}$ at $t=80 \mathrm{~min}$ was $63 \pm 4 \%$ in the control group and $63 \pm 1 \%$ in the 3 -NP group. Therefore plasma glucose FE was very stable and no significant difference was observed between the two groups. Plasma glucose $\mathrm{FE}$ at $t=2.5 \mathrm{~min}$ was not measured, but glucose concentrations at this time point indicate that there may be a small transient overshoot in FE (69\% in the control group and $73 \%$ in the 3 -NP group at $t=2.5 \mathrm{~min})$. The potential effect of such an overshoot in FE can be shown to be negligible (see sensitivity analysis in the results section).

\section{In vivo NMR spectroscopy}

All in vivo spectra were acquired on a Bruker Avance 3 Tesla wholebody spectrometer equipped with a head gradient insert reaching $25 \mathrm{mT} / \mathrm{m}$ in $170 \mu \mathrm{s}$. The double concentric surface probe consisted of a ${ }^{1} \mathrm{H}$ loop (diameter $1.2 \mathrm{~cm}$ ) for emission and reception and a larger ${ }^{13} \mathrm{C}$ loop (3 $\mathrm{cm}$ diameter) for editing and decoupling.

In vivo glutamate labelling time courses were acquired using the semiselective proton-observed carbon-edited (SPOCE) sequence as described previously (Henry et al. 2000). After acquisition of T1 coronal images, a $9 \times 4 \times 9 \mathrm{~mm}(360 \mu \mathrm{L})$ voxel was selected in the brain, centered on corpus callosum. Localization was achieved using (i) a slice-selective excitation in y direction and (ii) outer volume suppression by applying six slice-selective hyperbolicsecant excitation pulses followed by dephasing gradients. Separate glutamate $\mathrm{C} 4$ and glutamate $\mathrm{C} 3$ spectra were obtained simultaneously by combining the individual spectra A, B, C, D of the SPOCE method directly in the time domain before Fourier transform. Spectral processing consisted of $5 \mathrm{~Hz}$ lorentzian line broadening and manual baseline correction. Peak height was measured at 2.34 parts per million (ppm) and $2.09 \mathrm{ppm}$ in order to derive the labelling time courses of glutamate $\mathrm{C} 4$ and $\mathrm{C} 3$ in arbitrary units. Finally, glutamate $\mathrm{C} 4$ and $\mathrm{C} 3$ time courses were scaled to match 
the $\left[4-{ }^{13} \mathrm{C}\right]$ glutamate and $\left[3-{ }^{13} \mathrm{C}\right]$ glutamate concentrations measured on extracts at $t=120 \mathrm{~min}$.

\section{NMR of brain extracts}

After 120 min of glucose infusion, animals were killed and the brain was quickly removed. One hemisphere was immediately frozen in liquid nitrogen for high-resolution NMR analysis. The frozen hemisphere was crushed in a mortar and metabolites were extracted in $5 \mathrm{~mL}$ of an ice-cold $0.1 \mathrm{M}$ perchloric acid solution. Samples were then centrifuged $\left(15000 \mathrm{~g}, 4^{\circ} \mathrm{C}, 15 \mathrm{~min}\right)$ and the supernatants were neutralized with $5 \mathrm{~m}$ sodium hydroxide. After a second centrifugation $\left(15000 \mathrm{~g}, 4^{\circ} \mathrm{C}, 15 \mathrm{~min}\right)$, the supernatants were lyophilized and resuspended in $500 \mu \mathrm{L} \mathrm{D}_{2} \mathrm{O}$. High-resolution spectra were obtained on a vertical Bruker $7 \mathrm{~T}$ spectrometer. For each animal, four highresolution spectra were measured: one proton spectrum at $\mathrm{pH}=7$, one proton spectrum at $\mathrm{pH}=1$, one proton-observed carbon-edited (POCE) spectrum at $\mathrm{pH}=1$ and one direct carbon spectrum at $\mathrm{pH}=7$. Proton spectra were acquired using a simple pulse-acquire sequence (pulse width $8.6 \mu \mathrm{s}$, TR $15 \mathrm{~s}, 16$ scans, number of points 8192, spectral width $4000 \mathrm{~Hz}$ ) with WALTZ-16 carbon decoupling. POCE spectra were acquired using a spin-echo on the proton channel and a $180^{\circ}$ inversion every other scan on the carbon channel. TE was set to $1 / \mathrm{J}_{\mathrm{CH}}=7.8 \mathrm{~ms}$, corresponding to the $\mathrm{J}_{\mathrm{CH}}$ heteronuclear scalar coupling value of glutamate $(130 \mathrm{~Hz})$. For direct ${ }^{13} \mathrm{C}$ spectra, a pulse-acquire sequence with NOE enhancement and WALTZ-16 proton decoupling was used. (TR $2 \mathrm{~s}, 36000$ 166000 scans). No correction was necessary for differential saturation or NOE enhancement.

Metabolite concentrations were derived from the proton spectra. NAA, glutamate and glutamine were measured at $\mathrm{pH}=1$ (Fig. 1b), and aspartate at $\mathrm{pH}=7$ (Fig. 1a). The advantage of the spectrum (a)

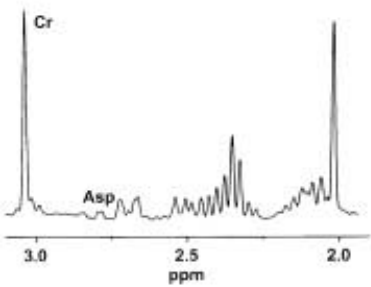

(c)

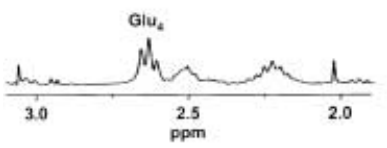

(b)

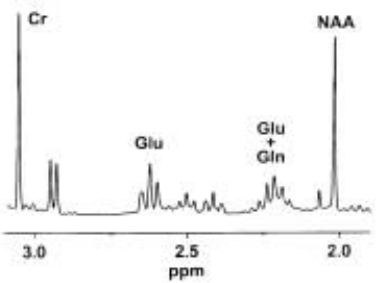

(d)

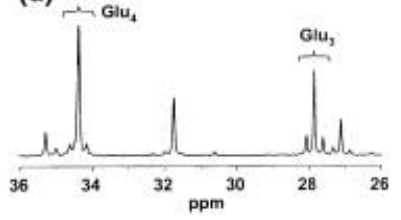

Fig. 1 Brain extracts spectra used for quantitation of metabolite concentrations and ${ }^{13} \mathrm{C}$ fractional enrichments. (a) ${ }^{1} \mathrm{H}$ spectrum at $\mathrm{pH}=7$ with ${ }^{13} \mathrm{C}$ decoupling. (b) ${ }^{1} \mathrm{H}$ spectrum at $\mathrm{pH}=1$ with ${ }^{13} \mathrm{C}$ decoupling. (c) Proton-observed carbon edited (POCE) difference spectrum at $\mathrm{pH}=1$ with ${ }^{13} \mathrm{C}$ decoupling. (d) Direct ${ }^{13} \mathrm{C}$ spectrum with ${ }^{1} \mathrm{H}$ decoupling and NOE. See Methods for details on the quantification procedure. All shown spectra were obtained from the same control animal. Glu, glutamate; Gln, glutamine; NAA, N-acetyl-aspartate; Lac, lactate. acquired at $\mathrm{pH}=1$ is that the glutamate $\mathrm{C}_{(4)} \mathrm{H} 2$ triplet is shifted to around $2.6 \mathrm{ppm}$ and can then be measured without contamination by glutamine. The concentration of glutamine was measured by integrating the total signal Glu + Gln (Fig. 1b) and subtracting glutamate concentration. All peaks were integrated relative to the creatine peak at $3.03 \mathrm{ppm}$ after manual baseline correction using the spectrometer software. Because the protein concentration in extracts was not measured in this study, it was not possible to obtain absolute concentrations. Therefore, creatine was used as an internal standard and its concentration was assumed to be $8 \mu \mathrm{mol} / \mathrm{g}$ (Pfeuffer et al. 1999b). Creatine concentration has been shown to be unaffected by 3-NP treatment (Dautry et al. 2000).

Glutamate $\mathrm{C} 4 \mathrm{FE}$ was derived from the POCE spectra by measuring the ratio of $\left[4-{ }^{13} \mathrm{C}\right]$ glutamate (Fig. 1c) to total glutamate. A correction factor of $8 \%$ was applied to account for imperfect satellite inversion in the POCE sequence due to $\mathrm{B}_{1}$ inhomogeneity. This correction factor was determined from the high lactate signal resulting from post-mortem autolysis following decapitation.

Finally, glutamate C3 FE at $t=120 \mathrm{~min}$ was obtained from the direct ${ }^{13} \mathrm{C}$ spectra (Fig. 1d). The relative $\mathrm{FE}$ of glutamate $\mathrm{C} 3$ compared to $\mathrm{C} 4$ was measured by integrating the $\left[3-{ }^{13} \mathrm{C}\right]$ glutamate pseudo-triplet at $27.9 \mathrm{ppm}$ relative to the $\left[4-{ }^{13} \mathrm{C}\right]$ glutamate pseudotriplet at $34.4 \mathrm{ppm}$.

\section{SDH histochemistry}

The second hemisphere was frozen in isopentane at $-25^{\circ} \mathrm{C}$ and used for histochemical measurement of SDH inhibition as described previously (Brouillet et al. 1998). The frozen hemispheres were sectioned at $20 \mu \mathrm{m}$, mounted on glass microscope slides, air-dried for $30-60 \mathrm{~min}$, and kept at $-20^{\circ} \mathrm{C}$ for $1-2$ days before histochemical staining. SDH activity was measured using succinate as a specific substrate and nitro blue tetrazolium (NBT) as an electron acceptor. All sections were incubated for $10 \mathrm{~min}$ in phosphatebuffered saline at $37^{\circ} \mathrm{C}$ to activate $\mathrm{SDH}$, then rinsed and incubated at $37^{\circ} \mathrm{C}$ for $40 \mathrm{~min}$ in a reaction medium containing $0.3 \mathrm{~mm} \mathrm{NBT}$, $0.05 \mathrm{M}$ phosphate buffer $(\mathrm{pH} 7.6)$ and $0.05 \mathrm{~m}$ succinate. Sections were rinsed, air-dried, and analysed using a video analysis system (IMSTAR, Paris, France). Enzymatic activity was measured on a section $+1 \mathrm{~mm}$ posterior to bregma. The region of interest in the two other dimensions was chosen identical to the voxel used for spectroscopy. SDH activity was expressed as the optical density change per $40 \mathrm{~min}$.

\section{Metabolic modelling}

${ }^{13} \mathrm{C}$ incorporation into brain metabolites was modelled as shown on Fig. 2. This model is similar to those used previously to analyze ${ }^{13} \mathrm{C}$ glutamate labelling time courses (Chance et al. 1983; Mason et al. 1992; Yu et al. 1995). First, glucose is transported through the blood-brain barrier according to a reversible Michaelis-Menten kinetics (Gruetter et al. 1998). Transport parameters as determined in $\alpha$-chloralose anaesthetized rats $\left(K_{\mathrm{t}}=3.3 \mathrm{mmol} / \mathrm{L}\right.$ and $T_{\max }=2.7^{*} V_{\text {gly }}$ ) were used in the model (Choi et al. 2001). Brain glucose is then converted to pyruvate/lactate through glycolysis, and enters the TCA cycle through pyruvate dehydrogenase (PDH) at the rate $V_{\text {tca. }}$. The ${ }^{13} \mathrm{C}$ isotope subsequently labels the $\mathrm{C} 4$ position of $\alpha$-ketoglutarate. Glutamate $\mathrm{C} 4$ becomes labelled through exchange with $\alpha$-ketoglutarate at the rate $V_{\mathrm{x}}$. Glutamine is labelled through exchange with glutamate at the rate $V_{\text {gln }}$. The ${ }^{13} \mathrm{C}$ isotope is then 


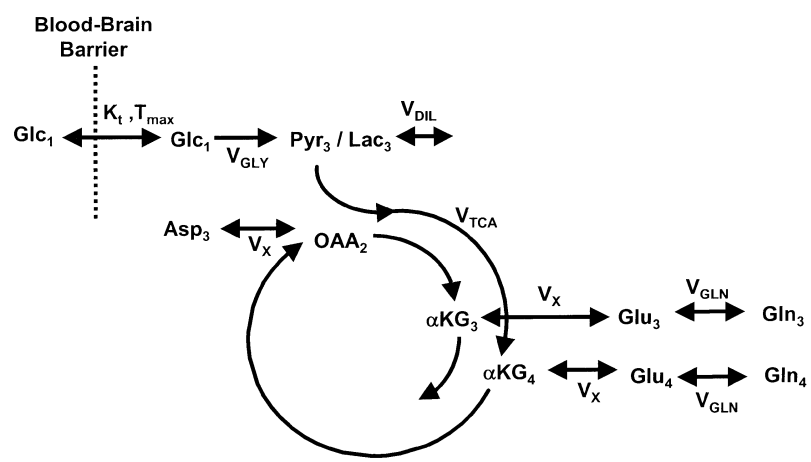

Fig. 2 Metabolic model describing the flow of ${ }^{13} \mathrm{C}$ label from $\left[1-{ }^{13} \mathrm{C}\right]$ glucose into glutamate. Glc, glucose; Pyr, pyruvate; Lac, lactate; aKG, $\alpha$-ketoglutarate; Glu, glutamate; Gln, glutamine; OAA, oxaloacetate; Asp, aspartate; $V_{\text {gly }}$, rate of glycolysis; $V_{\text {dil }}$, rate of exchange between labelled and unlabelled lactate; $V_{\text {tca, }}$, rate of TCA cycle; $V_{x}$, rate of exchange between $\alpha$-ketoglutarate and glutamate; $V_{\text {gln }}$, rate of exchange between glutamate and glutamine. See text for details.

incorporated into oxaloacetate $\mathrm{C} 2$ and $\mathrm{C} 3$. Aspartate becomes labelled through exchange with oxaloacetate at the rate $V_{\mathrm{x}}$ (equal to the exchange rate between $\alpha$-ketoglutarate and glutamate). In the second turn of the TCA cycle, $\alpha$-ketoglutarate, glutamate and glutamine are labelled in the $\mathrm{C} 3$ and $\mathrm{C} 2$ positions. A set of differential equations was obtained by expressing mass balance and isotope balance for each metabolite (see Appendix).

This model relies on the following assumptions:

The animals were assumed to be at metabolic steady state: all metabolite concentrations were considered as being constant throughout the experiment. The only exception is brain glucose, which concentration time course is modelled. Metabolic fluxes were also assumed to be constant.

Plasma glucose concentration was assumed to be $22 \mathrm{~mm}$ for $0<t<120 \mathrm{~min}$.

Plasma glucose fractional enrichment was assumed to be $63 \%$ for $0<t<120 \mathrm{~min}$.

The following fluxes were taken from the literature: $V_{\text {gly }}=0.5 \times V_{\text {tca }}, \quad V_{\text {dil }}=0.25 \times V_{\text {tca }}, \quad V_{\text {gln }}=0.46 \times V_{\text {tca }}$ (Mason et al. 1992; Sibson et al. 1997).

The following concentrations were taken from the literature: $[\mathrm{LAC}]=1 \mu \mathrm{mol} / \mathrm{g}, \quad[\alpha \mathrm{KG}]=0.5 \mu \mathrm{mol} / \mathrm{g}, \quad[\mathrm{OAA}]=1.1 \mu \mathrm{mol} / \mathrm{g}$ (Mason et al. 1992). Metabolites in fast exchange were considered as a single pool. For example the OAA pool includes all TCA cycle intermediates from $\alpha$-ketoglutarate to oxaloacetate.

All modelling results were obtained using the above assumptions, unless stated otherwise. The model was implemented using Matlab (The MathWorks, Inc, Natick, MA, USA). The differential equations were solved and the non-linear least squares fits were performed using built-in functions of Matlab. The least-squares cost function was defined as:

$$
\begin{aligned}
c= & \sum_{i}\left([\mathrm{GLUC} 4]_{\mathrm{data}}\left(t_{\mathrm{i}}\right)-[\mathrm{GLUC} 4]_{\text {model }}\left(t_{\mathrm{i}}\right)\right)^{2} \\
& +\sum_{i}\left([\mathrm{GLUC} 3]_{\mathrm{data}}\left(t_{\mathrm{i}}\right)-[\mathrm{GLUC} 3]_{\text {model }}\left(t_{\mathrm{i}}\right)\right)^{2}
\end{aligned}
$$

where $[\mathrm{GLUC} 4]_{\text {data }}\left(t_{\mathrm{i}}\right)$ and [GLUC3 $]_{\text {data }}\left(t_{\mathrm{i}}\right)$ represent the concentrations of $\left[4-{ }^{13} \mathrm{C}\right]$ glutamate and $\left[3-{ }^{13} \mathrm{C}\right]$ glutamate measured experi- mentally at time $t_{\mathrm{i}}$ whereas [GLUC4 $]_{\text {model }}\left(t_{\mathrm{i}}\right)$ and [GLUC3 $]_{\text {model }}\left(t_{\mathrm{i}}\right)$ represent the same concentrations calculated by the model.

The error on the fitted parameters $V_{\text {tca }}$ and $V_{\mathrm{x}}$ was evaluated using Monte-Carlo simulation. The fit residuals were obtained by subtracting the best fit curves of glutamate $\mathrm{C} 4$ and $\mathrm{C} 3$ from the data. Random noise values were generated with the same standard deviation as the residuals, and added to the fitted curves in order to generate a new dataset. The fit was then performed on this new dataset to yield new values of $V_{\text {tca }}$ and $V_{\mathrm{x}}$. This procedure was repeated 50 times for both the control and the 3-NP group. Finally, the standard deviation of the 50 values of $V_{\text {tca }}$ and $V_{\mathrm{x}}$ provided an estimate of the standard error on the fitted parameters.

\section{Statistical analysis}

All results are reported as mean $\pm \mathrm{SD}$. Differences between control and 3-NP groups were analysed using unpaired two-tailed Student's $t$-test. The only exception was for $V_{\text {tca }}$ and $V_{\mathrm{x}}$ values obtained from averaged time courses. In this case, the standard deviation was estimated by Monte-Carlo simulation, and a $z$-test was used to test differences between control and 3-NP groups.

\section{Results}

\section{Ex vivo data}

In the brain hemisphere used for histochemistry, the percentage of SDH inhibition (reduction of SDH activity as compared to control level) was $33 \pm 12 \%$ in the 3 -NP group, confirming that SDH was still inhibited $24 \mathrm{~h}$ after $3-\mathrm{NP}$ injection.

The plasma glucose fractional enrichment at the end of infusion was $63 \pm 2 \%$ in the control group and $62 \pm 2 \%$ in the 3-NP group.

The concentrations of NAA, glutamate, glutamine and aspartate, measured on extracts from the second hemisphere, are given in Table 1. NAA was significantly decreased in the 3-NP group as compared to the control group (unpaired $t$-test, $p<0.05)$.

Glutamate C4 FE at $t=120$ min was $24.1 \pm 1.0 \%$ in both control and 3-NP groups (Table 2). Glutamate C3 FE at $t=120 \mathrm{~min}$ was $17.9 \pm 1.1 \%$ in the control group and $17.0 \pm 1.0 \%$ in the 3 -NP group, showing that glutamate $\mathrm{C} 3$ was not at steady-state after $2 \mathrm{~h}$ of glucose infusion.

\section{In vivo data and metabolic modelling}

Figure 3 shows stacked plots of $\left[4-{ }^{13} \mathrm{C}\right]$ glutamate and $\left[3-{ }^{13} \mathrm{C}\right]$ glutamate spectra acquired in vivo on a control

Table 1 Brain concentration of major metabolites in $\mu \mathrm{mol} / \mathrm{g}$ wet weight (mean $\pm \mathrm{SD})$

\begin{tabular}{llrll}
\hline & NAA & \multicolumn{1}{l}{ Glu } & \multicolumn{1}{l}{ Gln } & \multicolumn{1}{l}{ Asp } \\
\hline Control $(n=5)$ & $7.5 \pm 0.6$ & $10.8 \pm 1.8$ & $4.0 \pm 0.8$ & $2.3 \pm 0.3$ \\
3-NP $(n=5)$ & $6.5 \pm 0.5^{\mathrm{a}}$ & $9.8 \pm 0.8$ & $4.3 \pm 1.1$ & $1.9 \pm 0.3$ \\
\hline
\end{tabular}

${ }^{\mathrm{a}} p<0.05$ versus control. 
Table $2{ }^{13} \mathrm{C}$ fractional enrichments of plasma glucose and brain glutamate at $\mathrm{t}=120 \mathrm{~min}($ mean $\pm \mathrm{SD})$

\begin{tabular}{llll}
\hline & Plasma glucose & Glutamate C4 & Glutamate C3 \\
\hline Control $(n=5)$ & $63 \pm 2$ & $24.1 \pm 1.3$ & $17.9 \pm 1.1$ \\
3-NP $(n=5)$ & $62 \pm 2$ & $24.0 \pm 1.6$ & $17.0 \pm 1.0$ \\
\hline
\end{tabular}

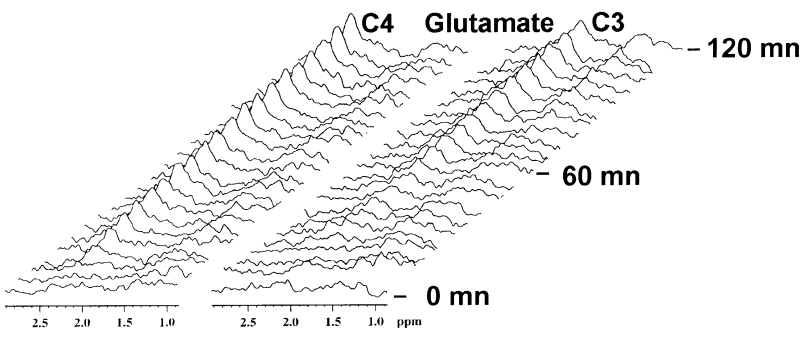

Fig. 3 In vivo ${ }^{13} \mathrm{C}$ labelling time course of glutamate $\mathrm{C} 4$ and $\mathrm{C} 3$ measured in rat brain during a 2-hour infusion of $\left[1-{ }^{13} \mathrm{C}\right]$ glucose. Separate C3 and C4 labelling time courses were obtained with the Semiselective POCE method. Spectral processing consisted of a $5-\mathrm{Hz}$ lorentzian line broadening.

animal during $\left[1-{ }^{13} \mathrm{C}\right]$ glucose infusion. The SPOCE sequence allowed the simultaneous and separate acquisition of glutamate $\mathrm{C} 4$ and $\mathrm{C} 3$ at 3 Tesla.

Figure 4( $a$ and $b$ ) shows the average labelling time courses of glutamate. Each dataset represents the averaged data of five animals. The continuous lines are the best fits of the
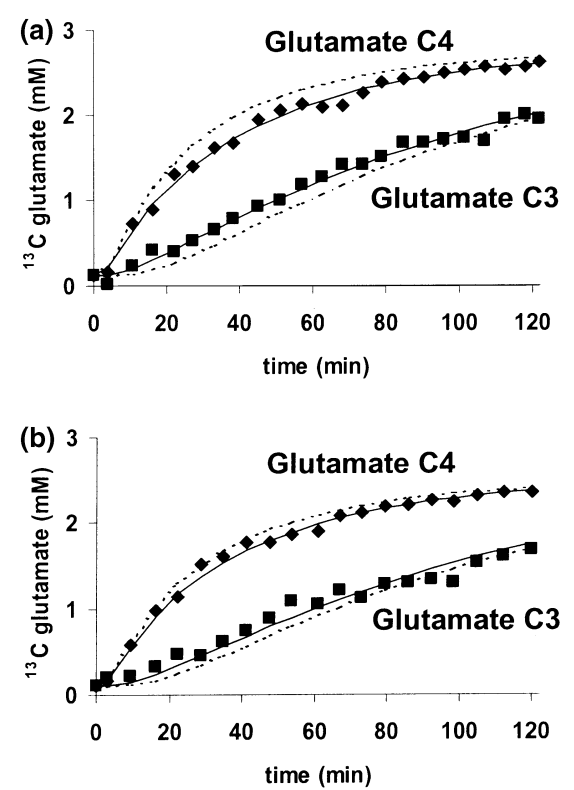

Fig. 4 In vivo glutamate C4 and C3 labelling time courses. (a) Control group; (b) 3-NP group. Each dataset is the average time course of five animals. Solid lines are the best fits to the data using the metabolic model described in the methods. Dashed lines are the best fits with the constraint $V_{\mathrm{x}}=50$.
Table 3 Values of fitted parameters $V_{\text {tca }}$ and $V_{\mathrm{x}}$ (mean $\pm \mathrm{SD}$ ) determined from the average glutamate time courses in the control and 3-NP group

\begin{tabular}{lll}
\hline & $V_{\text {tca }}$ & $V_{\mathrm{x}}$ \\
\hline Control & $0.71 \pm 0.02$ & $0.88 \pm 0.08$ \\
3-NP & $0.58 \pm 0.02^{\mathrm{a}}$ & $1.33 \pm 0.24^{\mathrm{b}}$
\end{tabular}

The standard deviations were obtained by Monte-Carlo simulation. ${ }^{\mathrm{a}} p<0.001,{ }^{\mathrm{b}} p<0.07$ versus control.

metabolic model to these data. The values of fitted parameters $V_{\text {tca }}$ and $V_{\mathrm{x}}$ are given in Table 3.

There is a highly significant $18 \%$ decrease in $V_{\text {tca }}$ from $0.71 \pm 0.02 \mu \mathrm{mol} / \mathrm{g} / \mathrm{min}$ in the control group to $0.58 \pm$ $0.02 \mu \mathrm{mol} / \mathrm{g} / \mathrm{min}$ in the 3 -NP group ( $z$-test, $p<0.001$ ). Due to the higher dispersion of $V_{\mathrm{x}}$ values, the difference in $V_{\mathrm{x}}$ is less significant between the two groups $(z$-test, $p<0.07)$, although $V_{\mathrm{x}}$ values appeared to be higher in the 3-NP group. Scatterplots of fitted parameters from Monte-Carlo simulations are shown on Fig. 5. These plots demonstrate that the dispersion of $V_{\mathrm{x}}$ values is much higher than the dispersion of $V_{\text {tca }}$ values.

Because $V_{\mathrm{x}}$ was reported to be much higher than $V_{\text {tca }}$ in several studies (Mason et al. 1992, 1995), the same fit was performed with $V_{\mathrm{x}}$ constrained to a higher value $\left(V_{\mathrm{x}}=50\right)$. The corresponding best fits show that, in this study, it was not possible to properly fit both glutamate $\mathrm{C} 4$ and $\mathrm{C} 3$ labelling time courses under the assumption that $V_{\mathrm{x}}$ is much higher than $V_{\text {tca }}$ (Figs $4 \mathrm{a}$ and $\mathrm{b}$, dashed lines).

To evaluate the benefit of fitting both glutamate $\mathrm{C} 4$ and C3 time courses, $V_{\text {tca }}$ was obtained by fitting the glutamate $\mathrm{C} 4$ time course only. Fitting the glutamate $\mathrm{C} 4$ time course while keeping both $V_{\text {tca }}$ and $V_{\mathrm{x}}$ as free parameters resulted in the fitted values becoming highly dependent on the

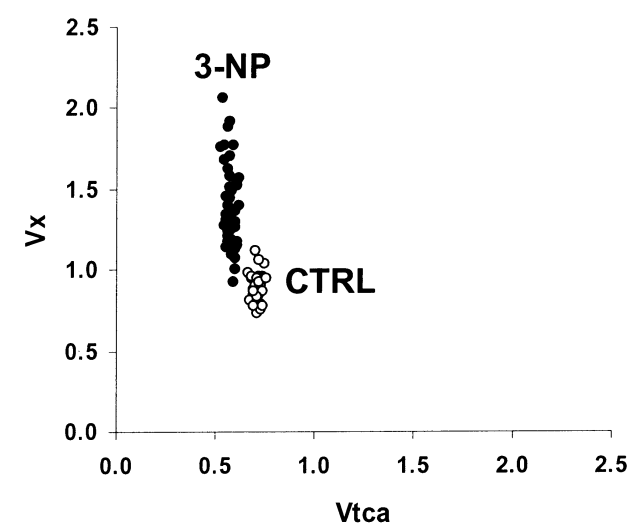

Fig. 5 Monte-Carlo analysis of the error in fitted parameters $V_{\text {tca }}$ and $V_{\mathrm{x}}$. The scatterplot shows the distribution of fitted values from average time courses for the control group $(\bigcirc)$ and the 3-NP group $(\bullet)$. The dispersion of $V_{\mathrm{x}}$ values is much higher than the dispersion of $V_{\text {tca }}$ values. 
initial conditions for the fit. Therefore the glutamate C4 time course alone does not provide enough information to determine both $V_{\text {tca }}$ and $V_{\mathrm{x}}$. Such a result is not unexpected given the relatively high correlation between these two parameters (Yu et al. 1997; Gruetter et al. 2001). Therefore, when only the glutamate $\mathrm{C} 4$ time course is available, an assumption must be made on the $V_{\mathrm{x}}$ value. First $V_{\mathrm{x}}$ was fixed to a high value $\left(V_{\mathrm{x}}=50\right) . V_{\text {tca }}$ values obtained under these conditions were $0.43 \mu \mathrm{mol} / \mathrm{g} / \mathrm{min}$ in both groups. When $V_{\mathrm{x}}$ was fixed to a lower value $\left(V_{\mathrm{x}}=1\right)$, the fitted value of $V_{\text {tca }}$ was $0.66 \mu \mathrm{mol} / \mathrm{g} / \mathrm{min}$ for the control group and $0.68 \mu \mathrm{mol} / \mathrm{g} / \mathrm{min}$ for the $3-\mathrm{NP}$ group (Fig. 6). Therefore, in both cases, fitting only $\mathrm{C} 4$ did not yield any significant difference between the two groups, whereas a significant difference appeared when fitting both $\mathrm{C} 4$ and $\mathrm{C} 3$ curves.

\section{Sensitivity analysis}

The effect of a change in some modelling parameters on the fitted values of $V_{\text {tca }}$ and $V_{\mathrm{x}}$ was examined. The corresponding values are summarized in Table 4 . Based on these results, we conclude that:

Fitting $V_{\text {dil }}$ at the same time as $V_{\mathrm{x}}$ and $V_{\text {tca }}$ yields $V_{\text {dil }}=0.27 V_{\text {tca }}$ in the control group and $V_{\text {dil }}=0.28 V_{\text {tca }}$ in the 3 -NP group, which justifies the assumption $V_{\text {dil }}=0.25 V_{\text {tca }}$ of our model. The constraint on $V_{\text {dil }}$ reduces numerical instabilities in the fitting procedure.

The effect of an overshoot in plasma glucose FE was evaluated as follows. Instead of being constant (63\%) for the whole time course, plasma glucose FE was assumed to decrease linearly from $69 \%$ at $t=0$ to $63 \%$ at $t=10 \mathrm{~min}$ in the control group and from $73 \%$ at $t=0$ to $63 \%$ at $t=10 \mathrm{~min}$ in the 3 -NP group. The $\mathrm{FE}$ values $69 \%$ and $73 \%$ were derived from the measured glucose concentrations at $t=0$ and $t=2.5 \mathrm{~min}$. The resulting effect on modelled $V_{\text {tca }}$ and $V_{\mathrm{x}}$ fluxes is negligible (see Table 4).
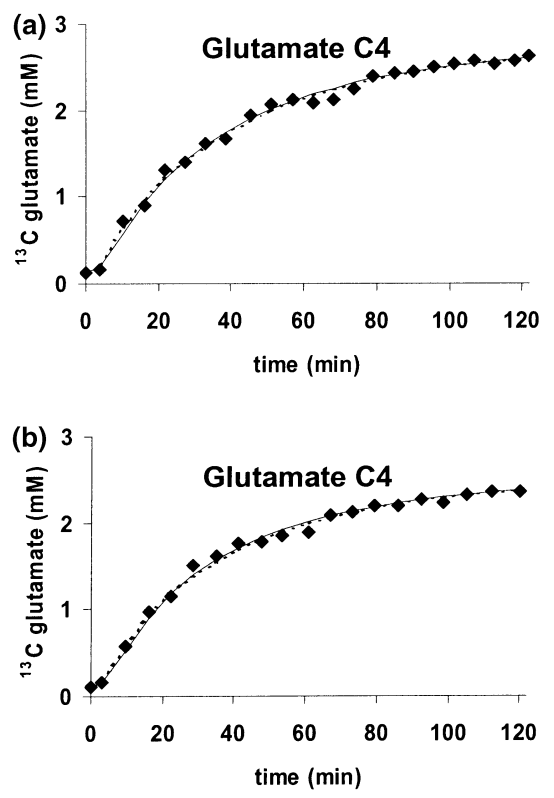

Fig. 6 Best fits to glutamate C4 labelling time courses only. (a) Control group; (b) 3-NP group. Solid lines are the best fits under the constraint $V_{\mathrm{x}}=50$. In this case the fitted $V_{\text {tca }}$ value is $0.43 \mu \mathrm{mol} / \mathrm{g} / \mathrm{min}$ in both groups. Dashed lines are the best fits with $V_{x}=1$. The fitted $V_{\text {tca }}$ value is then $0.66 \mu \mathrm{mol} / \mathrm{g} / \mathrm{min}$ in the control group and $0.68 \mu \mathrm{mol} / \mathrm{g} / \mathrm{min}$ in the 3-NP group.

A $50 \%$ decrease in $V_{\text {gln }}$ has negligible effect on $V_{\text {tca }}$ and $V_{\mathrm{x}}$ values. Therefore, the assumed value for $V_{\text {gln }}$ in the modelling is not critical.

A $10 \%$ change in glutamate concentration in the modelling induces $5.5-8 \%$ changes in $V_{\text {tca }}$ and $V_{\mathrm{x}}$ values.

Finally, a $10 \%$ change in the scaling of the C3 curve relative to the $\mathrm{C} 4$ curve induces $16-22 \%$ changes in $V_{\text {tca }}$ and $18-72 \%$ changes in $V_{\mathrm{x}}$ values. This demonstrates the importance of scaling the glutamate time courses correctly

Table 4 Sensitivity analysis

\begin{tabular}{|c|c|c|c|c|c|}
\hline & $\begin{array}{l}V_{\text {tca }} \\
\text { Control }\end{array}$ & $\begin{array}{l}V_{\mathrm{x}} \\
\text { Control }\end{array}$ & $\begin{array}{l}V_{\text {tca }} \\
\text { 3-NP }\end{array}$ & $\begin{array}{l}V_{\mathrm{x}} \\
\text { 3-NP }\end{array}$ & Comments \\
\hline Nominal parameters & 0.71 & 0.88 & 0.58 & 1.33 & \\
\hline$V_{\text {dil }}$ fitted at the same time as $V_{\text {tca }}$ and $V_{x}$ & 0.72 & 0.94 & 0.59 & 1.57 & $\begin{array}{l}V_{\text {dil }}=0.27 V_{\text {tca }}(\mathrm{ctrl}) \\
V_{\text {dil }}=0.28 V_{\text {tca }}(3-\mathrm{NP})\end{array}$ \\
\hline $50 \%$ decrease in $V_{\text {gln }}$ & 0.69 & 0.86 & 0.56 & 1.25 & \\
\hline 2 min delay before rise of plasma glucose & 0.75 & 1.00 & 0.61 & 1.61 & \\
\hline Overshoot in plasma glucose FE & 0.71 & 0.85 & 0.57 & 1.21 & \\
\hline $10 \%$ decrease in glutamate concentration & 0.67 & 0.81 & 0.55 & 1.21 & \\
\hline $10 \%$ increase in glutamate concentration & 0.75 & 0.95 & 0.61 & 1.41 & \\
\hline $10 \%$ decrease in $\mathrm{C} 3$ scaling relative to $\mathrm{C} 4$ & 0.59 & 1.20 & 0.49 & 2.24 & \\
\hline $10 \%$ increase in $\mathrm{C} 3$ scaling relative to $\mathrm{C} 4$ & 0.87 & 0.71 & 0.68 & 0.96 & \\
\hline
\end{tabular}

Nominal parameters refer to parameters used in the metabolic modelling to calculate $V_{\text {tca }}$ and $V_{\mathrm{x}}$ throughout this paper and are defined in the Materials and methods section. Fluxes are expressed in $\mu \mathrm{mol} / \mathrm{g} / \mathrm{min}$. 
as was done in this study by using glutamate FE at the end of glucose infusion as measured on extracts.

\section{Analysis of individual animals}

The choice of fitting the average time courses was made to minimize the effect of the noise in the data on the values of fitted parameters. The alternative is to fit each time course from each individual animal separately then average the values. The individual results are given in Table 5 .

The mean values of $V_{\text {tca }}$ are very similar to those found by fitting the average time courses, and do not depend much on initial conditions. However, the $V_{\mathrm{x}}$ values tend to be more unstable. The second 3-NP animal in Table 5, for which $V_{\mathrm{x}}=4.52$, demonstrates clearly the risk of instability when fitting individual time courses. For this particular animal, the fitted $V_{\mathrm{x}}$ value was highly dependent on initial conditions for the fit. In contrast, the values of $V_{\text {tca }}$ and $V_{\mathrm{x}}$ obtained from the average time courses were independent of initial conditions (less than $1 \%$ variation, not shown). When using the values from individual animals (with the initial conditions $V_{\mathrm{tca}}=0.1$ and $V_{\mathrm{x}}=0.1$ for example), $V_{\text {tca }}$ was reduced by $18 \%$ in the 3 -NP group compared to the control group ( $t$-test, $p=0.011)$ and $V_{\mathrm{x}}$ was increased with a low confidence level ( $t$-test, $p=0.18)$. The $p$-values are higher when fitting individual time courses than when fitting average time courses. This may result from interanimal biological variation, but more likely reflects the numerical instabilities and noise propagation when fitting each individual time course separately.

Table 5 Values of fitted parameters $V_{\text {tca }}$ and $V_{\mathrm{x}}$ for each individual animal, with different initial conditions for the fit

\begin{tabular}{llcll}
\hline & $\begin{array}{l}\text { Control } \\
V_{\text {tca }}\end{array}$ & $\begin{array}{l}\text { Control } \\
V_{\mathrm{x}}\end{array}$ & $\begin{array}{l}\text { 3-NP } \\
V_{\text {tca }}\end{array}$ & $\begin{array}{l}\text { 3-NP } \\
V_{\mathrm{x}}\end{array}$ \\
\hline Initial conditions: $V_{\text {tca }}=0.5$ and $V_{\mathrm{x}}=0.5$ & & \\
& 0.64 & 1.40 & 0.56 & 1.27 \\
& 0.75 & 1.21 & 0.52 & 4.52 \\
& 0.69 & 0.81 & 0.69 & 1.05 \\
& 0.80 & 0.68 & 0.54 & 1.20 \\
Mean & 0.70 & 0.68 & 0.60 & 1.18 \\
SD & 0.72 & 0.96 & 0.58 & 1.84 \\
& 0.06 & 0.33 & 0.07 & 1.50 \\
Initial conditions: $V_{\text {tca }}=0.1$ and $V_{\mathrm{x}}=0.1$ & & \\
& 0.64 & 1.41 & 0.56 & 1.19 \\
& 0.75 & 1.19 & 0.52 & 2.60 \\
& 0.69 & 0.81 & 0.69 & 1.07 \\
& 0.80 & 0.68 & 0.54 & 1.22 \\
Mean & 0.70 & 0.68 & 0.60 & 1.17 \\
SD & 0.72 & 0.95 & 0.58 & 1.45 \\
& 0.06 & 0.33 & 0.06 & 0.65 \\
\hline
\end{tabular}

\section{Discussion}

In this study, the quantitative effect of the mitochondrial toxin 3-NP on oxidative metabolism was examined using $\left\{{ }^{1} \mathrm{H}\right\}-{ }^{13} \mathrm{C}$ NMR spectroscopy in the rat brain. $V_{\text {tca }}$ was decreased by $18 \%$ in animals treated with $3-\mathrm{NP}$ as compared to control. Interestingly, this $V_{\text {tca }}$ decrease could be detected only when both glutamate $\mathrm{C} 4$ and $\mathrm{C} 3$ time course were included in the modelling. The rate of glutamate $\mathrm{C} 4$ turnover $\left(V_{\mathrm{gt}}\right)$ depends on both $V_{\text {tca }}$ and $V_{\mathrm{x}}$ and can be expressed as $V_{\mathrm{gt}}=V_{\mathrm{x}} \cdot V_{\mathrm{tca}} /\left(V_{\mathrm{x}}+V_{\mathrm{tca}}\right)$ (Mason et al. 1992). Using $V_{\text {tca }}$ and $V_{\mathrm{x}}$ values found in this study, $V_{\text {gt }}$ was $0.39 \mu \mathrm{mol} / \mathrm{g} / \mathrm{min}$ for the control group and $0.40 \mu \mathrm{mol} / \mathrm{g} / \mathrm{min}$ for the $3-\mathrm{NP}$ group. This is consistent with our finding that fitting the glutamate $\mathrm{C} 4$ time course alone did not reveal any difference between control and 3NP-treated animals. The similar value of $V_{\mathrm{gt}}$ in both groups also indicates that the decrease in $V_{\text {tca }}$ was compensated by an increase in $V_{\mathrm{x}}$ in the 3-NP group.

An unexpected result of this study was the low value of the $\alpha$-ketoglutarate/glutamate exchange rate $\left(V_{\mathrm{x}}=\right.$ $0.87 \mu \mathrm{mol} / \mathrm{g} / \mathrm{min}$ in the control group). Such a low $V_{\mathrm{x}}$ value has also been reported recently in the human brain (Gruetter et al. 2001). This is in contrast with the pioneering studies of Mason et al. (1992, 1995) which found $V_{\mathrm{x}}$ to be about $50 \mu \mathrm{mol} / \mathrm{g} / \mathrm{min}$ in both rat brain (Mason et al. 1992) and human brain (Mason et al. 1995). In the rat study, however, the animal was paralysed but not anaesthetized (except by $\mathrm{N}_{2} \mathrm{O}$ ), and the rate of glutamate turnover was much higher. Indeed, the glutamate $\mathrm{C} 4$ time course reached steady-state in only $20 \mathrm{~min}$ in non-anaesthetized rats, compared to $120 \mathrm{~min}$ in $\alpha$-chloralose anaesthetized rats. Therefore, one possible explanation to the different $V_{\mathrm{x}}$ values between the two studies could be that $V_{\mathrm{x}}$ is dependent on neuronal activity (Gruetter et al. 2001). The present study provides the first evidence that $V_{\mathrm{x}}$ can be rate-limiting in the anaesthetized adult rat brain. A low $V_{\mathrm{x}}$ to $V_{\text {tca }}$ ratio has long been observed in the heart (Yu et al. 1995). A number of detailed studies in the perfused heart have shown that, in this organ, $V_{\mathrm{x}}$ can be rate-limiting, and reflects primarily the transport of cytosolic glutamate and mitochondrial $\alpha$-ketoglutarate across the mitochondrial membrane (Yu et al. 1995, 1997). The brain relies on glucose for energy production, whereas the heart uses mainly fatty acids. This is expected to result in a more active malate-aspartate shuttle in the brain than in the heart. However, this is only an assumption and remains to be established in vivo. In addition, the extent to which the composite flux $V_{\mathrm{x}}$ reflects only malate-aspartate shuttle activity or other mechanisms in heart and brain is not known. The finding that $V_{\mathrm{x}}$ is comparable to $V_{\text {tca }}$ in the brain, as it is in the heart, should prompt further effort to address these issues. Finally, $V_{\mathrm{x}}$ has been shown to vary in response to physiological stimulation or in pathological conditions in the heart (Yu et al. 1996; Lewandowski et al. 1997). Our results 
suggest that this variability may hold in the brain as well and that $V_{\mathrm{x}}$ cannot be assumed to be constant in pathological conditions.

TCA cycle rate measurements by ${ }^{13} \mathrm{C}$ NMR have provided important new insights in functional neurochemistry, showing that $V_{\text {tca }}$ is increased during somatosensory stimulation (Hyder et al. 1996, 1997) and demonstrating a $1: 1$ stoichiometric relationship between glutamate-glutamine cycling and neuronal activity (Sibson et al. 1998; Shen et al. 1999). Most of these studies, however, have included only the $\mathrm{C} 4$ glutamate time course in the modelling and have determined $V_{\text {tca }}$ under the assumption that $V_{\mathrm{x}}$ is much higher than $V_{\text {tca. }}$ In this context, including the glutamate $\mathrm{C} 3$ labelling time course in the modelling would avoid any assumption on $V_{\mathrm{x}}$ value and may improve the accuracy on $V_{\text {tca. }}$ Recent improvements in hardware and methods, such as increased $B_{0}$ field strength, improved shimming and improved quantification, will facilitate the monitoring of ${ }^{13} \mathrm{C}$ incorporation into glutamate $\mathrm{C} 4$ and $\mathrm{C} 3$ in future studies.

The acute treatment protocol chosen for this study has been shown to induce a partial inhibition of SDH in the whole brain for more than $24 \mathrm{~h}$ (Brouillet et al. 1998). Histochemical measurements in our study confirmed that SDH activity at the end of glucose infusion was inhibited $(-33 \%)$ in 3-NP-treated animals compared to control animals. The decrease in $V_{\text {tca }}(-18 \%)$ induced by $3-N P$ treatment was almost twofold smaller than SDH inhibition $(-33 \%)$. This apparent discrepancy is not alarming and may simply reflect a situation where an enzyme (SDH) does not fully control the metabolic flux in a pathway (Kacser and Burns 1973). Besides the interest of 3-NP treatment as a model of Huntington's disease (Brouillet et al. 1999), the use of 3-NP combined with dynamic ${ }^{13} \mathrm{C}$ NMR might be a powerful tool for testing directly in vivo flux control theory.

NMR spectroscopy and histochemical measurements were performed about $24 \mathrm{~h}$ after 3-NP treatment to ensure that animals were at a metabolic steady-state (at the time scale of NMR measurement), a condition required for the metabolic modelling. Surprisingly, although succinate is known to rise sharply after 3-NP treatment, no significant increase of succinate could be detected in 3-NP-treated animals after $24 \mathrm{~h}$, either in vivo or in extracts. This indicates a short-term metabolic adaptation. After the initial rise, a slow decrease in succinate level can indeed be observed in in vivo measurements a few hours after acute 3-NP treatment (Lee et al. 2000). Similarly, although lactate has been shown to rise immediately after 3-NP treatment, no elevated lactate was observed on in vivo spectra $24 \mathrm{~h}$ after 3-NP injection.

A key point in 3-NP neurotoxicity, and also in HD, is to understand why neurones degenerate specifically in the striatum. Because SDH inhibition after 3-NP treatment is present in the whole brain, selective neurodegeneration cannot be explained by a selective inhibition of SDH in the striatum (Brouillet et al. 1998). However, there is some evidence that the TCA cycle is more affected by SDH inhibition in GABAergic neurones than in glutamatergic neurones or in astrocytes (Hassel and Sonnewald 1995). In particular, Hassel et al. showed that GABA and aspartate (both localized mainly in GABAergic neurones) labelling from $\left[1-{ }^{13} \mathrm{C}\right]$ glucose is affected by 3 -NP treatment in mice (Hassel and Sonnewald 1995). These measurements performed on brain extracts at one time point could be extended to in vivo measurements by monitoring the ${ }^{13} \mathrm{C}$ labelling time courses of GABA and aspartate. These two metabolites were not detectable in our study at 3 Tesla but have become accessible at very high magnetic field (Pfeuffer et al. 1999a).

A limitation of the present work, common to many noninvasive studies of the brain, is that the volume used for spectroscopy encompasses different regions of the brain, including parts of cortex, hippocampus and striatum. The single compartment model used for the analysis of NMR time courses does not take into account the possibility of regional or cellular heterogeneity with respect to 3-NP treatment. However, our goal in this first study was to determine if a global effect of 3-NP could be detected empirically with ${ }^{13} \mathrm{C}$ NMR using a simple monocompartment model. This approach was justified by the fact that SDH inhibition is homogeneous in the brain, although the effect of this SDH inhibition on $V_{\text {tca }}$ may not be homogeneous. Because most glutamate is in glutamatergic neurones, the decrease in $V_{\text {tca }}$ reported here may reflect primarily TCA cycle inhibition in glutamatergic neurones, with a minor contribution from GABAergic neurones. Alternatively, if TCA cycle inhibition is much higher in GABAergic neurones than in glutamatergic neurones, then the measured decrease in $V_{\text {tca }}$ will be an underestimate of the actual inhibition rate in GABAergic neurones. It is not possible with the present data to unravel the respective contributions of both compartments. Therefore it should be kept in mind that the decrease in $V_{\text {tca }}$ reported here is a composite effect reflecting possibly different TCA cycle inhibition rates in different compartments. Nonetheless this work demonstrates the feasibility of performing TCA cycle measurements in neurodegenerative disorders and opens the way to more detailed studies to understand the specific vulnerability of GABAergic neurones. For example, modelling GABA and aspartate time courses at higher magnetic field could provide an estimate of the TCA cycle inhibition in GABAergic neurones. Another possible extension of the present work could be to perform separate measurements of the TCA cycle rate in cortex and in striatum after 3-NP treatment in order to assess regional heterogeneity.

In conclusion, we report the first quantitative measurement of the TCA cycle rate in an animal model of neurodegenerative disorder using dynamic ${ }^{13} \mathrm{C}$ NMR spectroscopy. Our results show that $V_{\text {tca }}$ decreases and $V_{\mathrm{x}}$ increases in the rat brain after 3-NP treatment. The study demonstrates the importance of including sufficient information in the mathe- 
matical analysis to obtain a reliable measurement of $V_{\text {tca }}$ in pathological conditions. This approach can be extended to several other neurodegenerative disorders where impairment in energy metabolism is suspected (Beal 2000). Because ${ }^{13} \mathrm{C}$ NMR is a non-invasive technique, it could be used for patients (Blüml et al. 2001) and enlighten the biochemical mechanisms of neurodegeneration.

\section{Acknowledgements}

We would like to thank Dr Rolf Gruetter for useful comments, and Drs Graeme Mason and Douglas Rothman for helpful discussions. This work was supported by Commissariat a l'Energie Atomique, by Bruker Spectrospin SA (PGH), and by the European Community NeuroGet grant $n^{\circ}$ QLK3-CT-1999-00702 (VL).

\section{References}

Beal M. F. (2000) Energetics in the pathogenesis of neurodegenerative diseases. Trends Neurosci. 23, 298-304.

Beal M. F., Brouillet E., Jenkins B. G., Ferrante R. J., Kowall N. W., Miller J. M., Storey E., Srivastava R., Rosen B. R. and Hyman B. T. (1993) Neurochemical and histologic characterization of striatal excitotoxic lesions produced by the mitochondrial toxin 3-nitropropionic acid. J. Neurosci. 13, 4181-4192.

Blüml S., Moreno A., Hwang J. H. and Ross B. D. (2001) 1-(13) C glucose magnetic resonance spectroscopy of pediatric and adult brain disorders. NMR Biomed. 14, 19-32.

Brouillet E., Guyot M.-C., Mittoux V., Altairac S., Condé F., Palfi S. and Hantraye P. (1998) Partial inhibition of brain succinate dehydrogenase is sufficient to initiate striatal degeneration in rat. J. Neurochem. 70, 794-805.

Brouillet E., Condé F., Beal M. F. and Hantraye P. (1999) Replicating Huntington's disease phenotype in experimental animals. Prog. Neurobiol. 59, 427-468.

Chance M. C., Seeholzer S. H., Kobayashi K. and Williamson J. R. (1983) Mathematical analysis of isotope labeling in the citric acid cycle with applications to ${ }^{13} \mathrm{C}$ NMR studies in perfused rat hearts. J. Biol. Chem. 258, 13785-13794.

Chen W., Zhu X. H., Gruetter R., Seaquist E. R., Adriany G. and Ugurbil K. (2001) Study of tricarboxylic acid cycle flux changes in human visual cortex during hemifield visual stimulation using ${ }^{1} \mathrm{H}-\left\{{ }^{13} \mathrm{C}\right\}$ MRS and fMRI. Magn. Reson. Med. 45, 349-355.

Choi I.-Y., Lee S.-P., Kim S.-G. and Gruetter R. (2001) In vivo measurements of brain glucose transport using the reversible MichaelisMenten model and simultaneous measurements of cerebral blood flow changes during hypoglycemia. J. Cereb. Blood Flow Metab. 21, 653-663.

Dautry C., Conde F., Brouillet E., Mittoux V., Beal M. F., Bloch G. and Hantraye P. (1999) Serial ${ }^{1}$ H-NMR spectroscopy study of metabolic impairment in primates chronically treated with the succinate dehydrogenase inhibitor 3-nitropropionic acid. Neurobiol. Dis. 6, 259-268.

Dautry C., Vaufrey F., Brouillet E., Bizat N., Henry P.-G., Condé F., Bloch G. and Hantraye P. (2000) Early N-acetylaspartate depletion is a marker of neuronal death in rats and primates chronically treated with the mitochondrial toxin 3-nitropropionic acid. J. Cereb. Blood Flow Metab. 20, 789-799.

Gruetter R., Ugurbil K. and Seaquist E. R. (1998) Steady-state cerebral glucose concentrations and transport in the human brain. J. Neurochem. 70, 397-408.
Gruetter R., Seaquist E. R. and Ugurbil K. (2001) A mathematical model of compartmentalized neurotransmitter metabolism in the human brain. Am. J. Physiol. 281, E100-E112.

Harper P. S., ed. (1991) Huntington's Disease. WB Saunders, London.

Hassel B. and Sonnewald U. (1995) Selective inhibition of tricarboxylic acid cycle of GABAergic neurons with 3-nitropropionic acid in vivo. J. Neurochem. 65, 1184-1191.

Henry P.-G., Roussel R., Vaufrey F., Dautry C. and Bloch G. (2000) Semiselective POCE NMR spectroscopy. Magn. Reson. Med. 44, 395-400.

Hyder F., Chase J. R., Behar K. L., Mason G. F., Siddeef M., Rothman D. L. and Shulman R. G. (1996) Increased tricarboxylic acid cycle flux in the rat brain during forepaw stimulation detected with ${ }^{1} \mathrm{H}$ $\left[{ }^{13}\right.$ C] NMR. Proc. Natl. Acad. Sci. USA 93, 7612-7617.

Hyder F., Rothman D. L., Mason G. F., Rangarajan A., Behar K. L. and Shulman R. G. (1997) Oxidative glucose metabolism in rat brain during single forepaw stimulation: a spatially localized ${ }^{1} \mathrm{H}\left[{ }^{13} \mathrm{C}\right]$ nuclear magnetic resonance study. J. Cereb. Blood Flow Metab. 17, 1040-1047.

Hyder F., Renken R. and Rothman D. L. (1999) In vivo carbon-edited detection with proton echo-planar spectroscopic imaging (ICED PEPSI): $\left[3,4-{ }^{13} \mathrm{CH}_{2}\right]$ glutamate/glutamine tomography in rat brain. Magn. Reson. Med. 42, 997-1003.

Jenkins B. G., Brouillet E., Chen Y. C., Storey E., Schulz J. B., Kirschner P., Beal M. F. and Rosen B. R. (1996) Non-invasive neurochemical analysis of focal excitotoxic lesions in models of neurodegenerative illness using spectroscopic imaging. J. Cereb. Blood Flow Metab. 16, 450-461.

Kacser H. and Burns J. A. (1973) The control of flux. Symp Soc. Exp. Biol. 27, 65-104.

Lee W. T., Lee C. S., Pan Y. L. and Chang C. (2000) Temporal changes of cerebral metabolites and striatal lesions in acute 3-nitropropionic acid intoxication in the rat. Magn. Reson. Med. 44, 29-34.

Lewandowski E. D., Yu X., LaNoue K. F., White L. T., Doumen C. and O'Donnell J. M. (1997) Altered metabolite exchange between subcellular compartments in intact post-ischemic rabbit hearts. Circ. Res. 81, 165-175.

Mason G. F., Rothman D. L., Behar K. L. and Shulman R. G. (1992) NMR determination of the TCA cycle rate and $\alpha$-ketoglutarate/ glutamate exchange rate in rat brain. J. Cereb. Blood Flow Metab. 12, 434-447.

Mason G. F., Gruetter R., Rothman D. L., Behar K. L., Shulman R. G. and Novotny E. J. (1995) Simultaneous determination of the rates of the TCA cycle, glucose utilization, $\alpha$-ketoglutarate/glutamate exchange, and glutamine synthesis in human brain by NMR. J. Cereb. Blood Flow Metab. 15, 12-25.

Mason G. F., Pan J. W., Chu W.-J., Newcomer B. R., Zhang Y., Orr R. and Hetherington H. P. (1999) Measurement of the tricarboxylic acid cycle rate in human grey and white matter in vivo by ${ }^{1} \mathrm{H}-\left[{ }^{13} \mathrm{C}\right]$ magnetic resonance spectroscopy at 4.1T. J. Cereb. Blood Flow Metab. 19, 1179-1188.

Pfeuffer J., Tkac I., Choi I.-Y., Merkle H., Ugurbil K., Garwood M. and Gruetter R. (1999a) Localized in vivo ${ }^{1} \mathrm{H}$ NMR detection of neurotransmitter labeling in rat brain during infusion of $\left[1-{ }^{13} \mathrm{C}\right]$ D-glucose. Magn. Reson. Med. 41, 1077-1083.

Pfeuffer J., Tkac I., Provencher S. W. and Gruetter R. (1999b) Toward an in vivo neurochemical profile: quantification of 18 metabolites in short-echo-time (1)H NMR spectra of the rat brain. J. Magn. Reson. 141, 104-120.

Shen J., Petersen K. F., Behar K. L., Brown P., Nixon T. W., Mason G. F., Petroff O. A. C., Shulman G. I., Shulman R. G. and Rothman D. L. (1999) Determination of the rate of the glutamate/glutamine cycle in the human brain by in vivo ${ }^{13} \mathrm{C}$ NMR. Proc. Natl. Acad. Sci. USA 96, 8235-8240. 
Sibson N. R., Dhankhar A., Mason G. F., Behar K. L., Rothman D. L. and Shulman R. G. (1997) In vivo ${ }^{13} \mathrm{C}$ NMR measurements of cerebral glutamine synthesis as evidence for glutamate-glutamine cycling. Proc. Natl. Acad. Sci. USA 94, 2699-2704.

Sibson N. R., Dhankhar A., Mason G. F., Rothman D. L., Behar K. L. and Shulman R. G. (1998) Stoichiometric coupling of brain metabolism and glutamatergic neuronal activity. Proc. Natl. Acad. Sci. USA 95, 316-321.

Tsai M. J., Goh C. C., Wan Y. L. and Chang C. (1997) Metabolic alterations produced by 3-nitropropionic acid in rat striata and cultured astrocytes: quantitative in vitro $1 \mathrm{H}$ nuclear magnetic resonance spectroscopy and biochemical characterization. Neuroscience 79, 819-826.

Yu X., White L. T., Doumen C., Damico L. A., LaNoue K. F., Alpert N. M. and Lewandowski E. D. (1995) Kinetic analysis of dynamic ${ }^{13} \mathrm{C}$ NMR spectra: metabolic flux, regulation, and compartmentation in hearts. Biophys. J. 69, 2090-2102.

Yu X., White L. T., Alpert N. M. and Lewandowski E. D. (1996) Subcellular metabolite transport and carbon isotope kinetics in the intramyocardial glutamate pool. Biochemistry 35, 6963-6968.

Yu X., Alpert N. M. and Lewandowski E. D. (1997) Modeling enrichment kinetics from dynamic ${ }^{13} \mathrm{C}-\mathrm{NMR}$ spectra: theoretical analysis and practical considerations. Am. J. Physiol. 272, C2037-C2048

\section{Appendix}

\section{Mathematical expression of the metabolic model}

The model described in Fig. 1 can be expressed mathematically by writing the mass balance and isotope balance equations for each pool. Because all metabolite concentrations are assumed to be constant except for glucose, there is only one mass balance equation. This equation describes glucose transport across the blood-brain barrier according to the reversible Michaelis-Menten kinetics (Gruetter et al. 1998):

$$
\begin{aligned}
\frac{d[\mathrm{GLC}]_{\text {brain }}}{d t}= & T_{\max } \cdot \frac{[\mathrm{GLC}]_{\text {plasma }}}{K_{\mathrm{t}}+\frac{[\mathrm{GLC}]_{\text {brain }}}{V_{\mathrm{d}}}+[\mathrm{GLC}]_{\text {plasma }}} \\
& -T_{\max } \cdot \frac{[\mathrm{GLC}]_{\text {brain }}}{V_{\mathrm{d}} \cdot K_{\mathrm{t}}+V_{\mathrm{d}} \cdot[\mathrm{GLC}]_{\text {plasma }}+[\mathrm{GLC}]_{\text {brain }}} \\
& -V_{\text {gly }}
\end{aligned}
$$

where $K_{\mathrm{t}}$ is the apparent Michaelis-Menten constant, $T_{\max }$ is the maximal transport rate and $V_{\mathrm{d}}$ is the physical distribution space of glucose in the brain.

Isotope balance equations express that the amount of ${ }^{13} \mathrm{C}$ label entering each pool is equal to the amount of ${ }^{13} \mathrm{C}$ isotope exiting this pool:

$$
\begin{aligned}
& \frac{d[\mathrm{GLC} 1]_{\text {brain }}}{d t}=T_{\max } \cdot \frac{[\mathrm{GLC} 1]_{\text {plasma }}}{K_{\mathrm{t}}+\frac{[\mathrm{GLC} 1]_{\text {brain }}}{V_{\mathrm{d}}}+[\mathrm{GLC} 1]_{\text {plasma }}} \\
& -T_{\max } \cdot \frac{[\mathrm{GLC} 1]_{\text {brain }}}{V_{\mathrm{d}} \cdot K_{\mathrm{t}}+V_{\mathrm{d}} \cdot[\mathrm{GLC} 1]_{\text {plasma }}+[\mathrm{GLC} 1]_{\text {brain }}} \\
& -V_{\mathrm{gly}} \cdot \frac{[\mathrm{GLC} 1]}{[\mathrm{GLC}]} \\
& \frac{d[\mathrm{~L} 3]}{d t}=V_{\mathrm{gly}} \cdot \frac{[\mathrm{GLC} 1]_{\mathrm{brain}}}{[\mathrm{GLC}]_{\mathrm{brain}}}-\left(V_{\mathrm{tca}}+V_{\mathrm{dil}}\right) \cdot \frac{[\mathrm{L} 3]}{[\mathrm{L}]}+0.011 \cdot V_{\mathrm{dil}} \\
& \frac{d[\alpha \mathrm{KG} 4]}{d t}=V_{\mathrm{tca}} \cdot \frac{[\mathrm{L} 3]}{[\mathrm{L}]}+V_{\mathrm{x}} \cdot \frac{[\mathrm{GLU} 4]}{[\mathrm{GLU}]}-\left(V_{\mathrm{tca}}+V_{\mathrm{x}}\right) \cdot \frac{[\alpha \mathrm{KG} 4]}{[\alpha \mathrm{KG}]} \\
& \frac{d[\alpha \mathrm{KG} 3]}{d t}=V_{\mathrm{tca}} \cdot \frac{[\mathrm{OAA} 2]}{[\mathrm{OAA}]}+V_{\mathrm{x}} \cdot \frac{[\mathrm{GLU} 3]}{[\mathrm{GLU}]} \\
& -\left(V_{\text {tca }}+V_{\mathrm{x}}\right) \cdot \frac{[\alpha \mathrm{KG} 3]}{[\alpha \mathrm{KG}]} \\
& \frac{d[\mathrm{GLU} 4]}{d t}=V_{\mathrm{x}} \cdot \frac{[\alpha \mathrm{KG} 4]}{[\alpha \mathrm{KG}]}-\left(V_{\mathrm{x}}+V_{\mathrm{gln}}\right) \cdot \frac{[\mathrm{GLU} 4]}{[\mathrm{GLU}]} \\
& +V_{\mathrm{gln}} \cdot \frac{[\mathrm{GLN} 4]}{[\mathrm{GLN}]} \\
& \frac{d[\mathrm{GLU} 3]}{d t}=V_{\mathrm{x}} \cdot \frac{[\alpha \mathrm{KG} 3]}{[\alpha \mathrm{KG}]}+\left(V_{\mathrm{x}}+V_{\mathrm{gln}}\right) \cdot \frac{[\mathrm{GLU} 3]}{[\mathrm{GLU}]} \\
& +V_{\operatorname{gln}} \cdot \frac{[\mathrm{GLN} 3]}{[\mathrm{GLN}]} \\
& \frac{d[\mathrm{OAA} 2]}{d t}=\frac{1}{2} V_{\mathrm{tca}} \cdot\left(\frac{[\alpha \mathrm{KG} 4]}{[\alpha \mathrm{KG}]}+\frac{[\alpha \mathrm{KG} 3]}{[\alpha \mathrm{KG}]}\right) \\
& +V_{\mathrm{x}} \cdot \frac{[\mathrm{ASP} 2]}{[\mathrm{ASP}]}-\left(V_{\mathrm{tca}}+V_{\mathrm{x}}\right) \cdot \frac{[\mathrm{OAA} 2]}{[\mathrm{OAA}]} \\
& \frac{d[\mathrm{ASP} 2]}{d t}=V_{\mathrm{x}} \cdot\left(\frac{[\mathrm{OAA} 2]}{[\mathrm{OAA}]}-\frac{[\mathrm{ASP} 2]}{[\mathrm{ASP}]}\right) \\
& \frac{d[\mathrm{GLN} 4]}{d t}=V_{\mathrm{gln}} \cdot\left(\frac{[\mathrm{GLU} 4]}{[\mathrm{GLU}]}-\frac{[\mathrm{GLN} 4]}{[\mathrm{GLN}]}\right) \\
& \frac{d[\mathrm{GLN} 3]}{d t}=V_{\mathrm{gln}} \cdot\left(\frac{[\mathrm{GLU} 3]}{[\mathrm{GLU}]}-\frac{[\mathrm{GLN} 3]}{[\mathrm{GLN}]}\right)
\end{aligned}
$$

In the above equations, $[\mathrm{XXX}]$ represents the total concentration of metabolite XXX whereas [XXXn] represents the concentration of metabolite XXX labelled on carbon n. For example [GLU] is the total glutamate concentration and [GLU4] is the concentration of $\left[4-{ }^{13} \mathrm{C}\right]$ glutamate. All other symbols are defined in the legend of Fig. 1. 